\title{
NOVO TEMPO - A EXPERIÊNCIA DE IMPLANTAÇÃO DO PROGRAMA DE PREPARAÇÃO PARA O PÓS-CARREIRA NO IFRN
}

\author{
T. M. F. R. A. PEREIRA ${ }^{1}$ e S. S. GUEDES ${ }^{2}$ \\ ${ }^{1,2}$ Instituto Federal de Educação, Ciência e Tecnologia do Rio Grande do Norte \\ thelma.rabelo@ifrn.edu.br ${ }^{1}$; suerdaguedes@ifrn.edu.br ${ }^{2}$
}

Artigo submetido em setembro/2011 e aceito em setembro/2012

\section{RESUMO}

Os momentos que antecedem à aposentadoria se constituem em um processo único e diferenciado para cada pessoa. Porém, o fato de estarmos inseridos em uma sociedade que supervaloriza o trabalho e o papel profissional e que não nos prepara para uma vivência satisfatória do tempo livre, tem concorrido para transformar a hora do desligamento da atividade laboral em momentos de angústia, que mobilizam medos, dúvidas e muitas inquietações. Este artigo relata um estudo de caso sobre a experiência de implantação, a partir de 2008, do "Novo Tempo - Programa de Preparação para o Pós-Carreira", do Instituto Federal de Educação, Ciência e Tecnologia do Rio Grande do Norte/Câmpus Natal-Central -, que tem como objetivo capacitar os servidores que estejam há três anos da aposentadoria a lidar com o término da atividade institucional com competência e criatividade. Mostrar- se-á a experiência de implantação, planejamento de atividades e detalhamento do funcionamento do Programa Novo Tempo, e o atingimento de seus objetivos. Para os fins deste artigo, adotou-se uma estratégia metodológica de caráter descritivo, envolvendo o uso de técnicas padronizadas de gravações e aplicação de questionários, através dos quais foram colhidos os depoimentos dos participantes de cada uma das três turmas concluintes. Com base nestes relatos, conclui-se que o Programa tem sido um importante facilitador nas tomadas de decisão e na conscientização da necessidade de planejamento de um projeto de vida voltado para uma aposentadoria ativa no pós-carreira, corroborando a relevância deste tipo de ação de responsabilidade social por parte das organizações.

PALAVRAS-CHAVE: Aposentadoria - Preparação - Pós-Carreira

\section{NEW TIME - THE EXPERIENCE OF IMPLEMENTING THE PREPARATION PROGRAM FOR THE POST-CAREER AT IFRN}

\begin{abstract}
Moments before retirement comprise a unique process and it differs from person to person. Nevertheless, as we are part of a society which overrates the labor and the professional role and which does not prepare us for satisfactory experience of free time, this has contributed to transform the time when you stop working into moments of stress, that brings fear, doubts and much of a bother. This paper reports a case study about the experience of program implementation entitled: "New Time - Preparation Program for the Post-career", started in 2008 at the Federal Institute of Education, Science and Technology of the state of Rio Grande do Norte/Central Campus Natal, which has the goal of allowing workers, who will retire within three years, to deal with the end of their institutional activity
\end{abstract}

competently and with creativity. The implementation experience, the activities planning, the New Time Program detailing operation, and their goals achievements will be displayed. For the purposes of this article, we adopted a descriptive methodology, involving the use of standardized techniques of recording and questionnaires, which were collected through the testimonies of participants in each of the three graduating classes. It concludes that the program has proved to be an important facilitator in decision making and awareness of the need for planning a life project directed to an active retirement at post-career, corroborating to the relevance of this type of social responsibility action made by the organizations. 


\section{NOVO TEMPO - A EXPERIÊNCIA DE IMPLANTAÇÃO DO PROGRAMA DE PREPARAÇÃO PARA O PÓS-CARREIRA NO IFRN}

\section{INTRODUÇÃO}

A partir do momento em que nasce, o homem já tem seu destino traçado: ser trabalhador. O imaginário popular, desde sempre, está eivado de expressões como "o trabalho dignifica o homem", "Deus ajuda a quem cedo madruga", "o trabalho é quem faz o homem"... que nos acompanham vida a fora. Assim, somos aculturados e imersos em estruturas e representações sociais que, de modo algum, preparam o sujeito para envelhecer ou para o afastamento do mundo reconhecido socialmente: o mundo do trabalho. Ou seja, o trabalho não representa unicamente um meio de sobrevivência, mas funciona como elemento socializador e fundante, que garante ao homem sua identidade social.

Assim, abandonar o papel profissional não se constitui tarefa fácil, considerando que vivemos em uma sociedade que supervaloriza o trabalho e despreza o tempo livre; somos educados para trabalhar, e não para o lazer ou para o descanso. $O$ ócio nos traz sentimentos de culpa e de inadequação - não aprendemos que "a preguiça é a mãe de todos os vícios"; e que "mente desocupada é oficina do diabo"? Enfim, somos ensinados a começar a trabalhar, mas não nos ensinam como fazer na hora de parar.

Devido a essa importante significação social conferida ao trabalho, é compreensível que a chegada da aposentadoria possa trazer rupturas e crises identitárias a pessoas que passaram a vida tentando responder à pergunta: "O que você vai ser quando crescer?". Para Santos (1990), a dificuldade em se afastar do trabalho vai ser proporcional à centralidade do papel profissional na vida do sujeito e à valorização dada ao status conferido pela identidade institucional. Ou seja, quanto maior o apego, maior o sofrimento na hora do desligamento da atividade laboral.

Este artigo relata um estudo de caso sobre a experiência de implantação do Novo Tempo Programa de Preparação para o Pós-Carreira, do IFRN/Campus Natal-Central, detalhando o planejamento das atividades utilizadas, a metodologia aplicada e o atingimento dos objetivos. Para tanto, discorre-se sobre o momento de sua criação, as dificuldades e resistências enfrentadas, a adesão dos participantes, além dos pressupostos teóricos-epistemológicos que orientam os conteúdos e as técnicas utilizadas durante o curso.

Inicialmente, serão apresentados os enfrentamentos e dilemas da pré-aposentadoria e os significados e as relações existentes entre identidade, trabalho e envelhecimento. Na sequência, será mostrado o surgimento dos Programas de Preparação para o Pós-Carreira no Brasil, com foco na experiência de implantação do Programa Novo Tempo no IFRN, com detalhamento da metodologia adotada e do planejamento das atividades e descrição dos módulos temáticos. Os depoimentos que ilustram o artigo foram colhidos através de gravações e aplicação de questionários junto aos participantes das três turmas, nos momentos destinados à avaliação final do curso. 
Finalizando, é crescente o número de organizações no Brasil e no mundo, dentro de sua política de gestão de pessoas, que tem se preocupado com o processo de aposentadoria de seus funcionários. Neste cenário, a preparação para o pós-carreira é um recurso que vem sendo disponibilizado pelas organizações para compreender as expectativas e ansiedades que caracterizam o período da pré-aposentadoria, objetivando levar os pré-aposentados a compartilharem entre si um momento de vida que tem muitas semelhanças, e que oferece oportunidades para o desenvolvimento pessoal, descobertas de potencialidades e fontes de prazer e crescimento pessoal: o pós-carreira.

\section{ENFRENTAMENTOS E DILEMAS DA PRÉ-APOSENTADORIA}

Compreender o ato de aposentar-se nos remete às definições encontradas na literatura para o vocábulo "aposentadoria": "Estado de inatividade de funcionário público ou de empresa particular, ao fim de certo tempo de serviço, com determinado vencimento; reforma." (AURÉLIO, 2002). Etimologicamente, aposentar-se vem do verbo latino intransitivo "pausare", que significa pousar, parar, cessar, descansar, tomar aposento (FILHO, 2011). Considerando que aposento significa quarto, alcova, aposentar-se sugere, então, recolher-se ao quarto, a casa. Em francês e em inglês (retraité e retired, respectivamente), também correspondem a palavras que significam retirar-se, isolar-se, recolher-se - enfim, hora de ir embora. Mas, para onde?

Como se pode observar, as definições citadas refletem representações sociais que terminam por vincular a aposentadoria a vivências de inutilidade, improdutividade, recolhimento. Estereótipos negativos que induzem a crer que "não há vida após a aposentadoria", são responsáveis, em grande parte, pelos comportamentos de isolamento e sentimentos de inadequação vivenciados por muitos dos que se aposentam. (CARLOS, S. et al, 1999; SOARES et al, 2007). Vale salientar, no entanto, que expressiva parcela dos aposentados brasileiros luta para permanecer no mercado de trabalho, em função de pressões econômicas, sociais e culturais, considerando-se o baixo valor dos proventos pagos pelo Instituto Nacional de Seguridade Social - INSS (SHIBATA, 2006). Segundo dados do último censo do IBGE, a participação dos aposentados no mercado de trabalho chegou a 8,2\% em 2010 - o que significa que 7,2 milhões de aposentados estão no mercado de trabalho no Brasil.

Reconhecida como um evento normativo que faz parte da vida de todo trabalhador, a aposentadoria é considerada, pela Teoria do Desenvolvimento para a Vida Toda (Life-Span Development), como a ocorrência mais importante da fase que antecede o envelhecimento (BALTES \& BALTES, 1990). A chegada da aposentadoria configura-se como um momento único, delicado, de transição e de mudanças. É o momento em que os indivíduos devem começar a planejar uma nova etapa na vida e decidir, em função dela, a melhor hora para se afastar do trabalho. A essa fase, Stucchi (2003) denomina de pré-aposentadoria.

A forma como cada um vai vivenciar este momento irá variar de pessoa para pessoa, e sofrerá influências da cultura, dos valores pessoais e sócio-econômicos do lugar onde se vive (FRANÇA, 2008). Para a maioria, entretanto, é uma fase permeada por sentimentos confusos e ambivalentes, que mobiliza apreensão, angústia, dúvidas, alternâncias de humor, doenças psicossomáticas e medos diversos: de perder o status de "estar na ativa"; do isolamento que pode advir da falta de contato com os colegas e com o ambiente de trabalho; da perda do papel 
profissional; da diminuição do padrão de vida anterior; medo de não saber como ocupar o tempo livre; ansiedade em relação ao retorno para casa.

Mas, por que é tão difícil falar em aposentadoria? Por que a aposentadoria assusta tanto? Shibata (2006) observa que, quando nos propomos a dialogar sobre o tempo do pós-carreira, a maioria das pessoas se esquiva, como se a aposentadoria fosse algo externo e que só diz respeito ao outro.

Para Santos (1990), a chegada da aposentadoria pode gerar sentimentos tanto de crise quanto de libertação. Crise pela recusa em identificar-se com o estigma que associa aposentadoria à velhice e à inatividade; e libertação, diante da possibilidade da concretização de planos anteriormente não realizados. Segundo Witczak (2005), esta ambiguidade pode vir na forma de sensação de liberdade pelo fato das pessoas não estarem mais presas ao relógio, concomitantemente ao peso da falta de uma rotina habitualmente estruturada em anos de trabalho.

O fato da ONU classificar cronologicamente o início da chamada "Terceira Idade" aos 60 anos para países em desenvolvimento, e aos 65 anos para países desenvolvidos - idades simultâneas aos processos de aposentadoria que ocorrem na maioria dos países -, termina por reforçar a associação que o senso comum faz entre aposentadoria e envelhecimento, embora, na prática, uma coisa não signifique, necessariamente, a outra. Luborsky e LeBlanc (2003) apud França (2008, p.47) esclarecem que "a aposentadoria difere do envelhecimento - nem todos os aposentados são velhos, e nem toda a velhice é aposentada". No imaginário social, porém, a aposentadoria é tida como um rito de passagem, uma espécie de passaporte para a entrada na chamada "Terceira Idade". Enfrentar o estigma de, após aposentado, ser considerado "velho" incluindo toda a carga negativa que esta palavra carrega em nossa sociedade - é, portanto, uma das tarefas mais árduas da aposentadoria. Zanelli, Silva \& Soares (2010, p. 96) recomendam aos participantes dos cursos de preparação para o pós-carreira "atuarem com a finalidade de tomar consciência e rever os próprios valores e firmar estratégias de resistências a internalizações autodepreciativas. É preciso manter a autoestima elevada, e não se deixar levar pelas pressões do contexto social".

\section{IDENTIDADE, TRABALHO E ENVELHECIMENTO: SIGNIFICADOS E RELAÇÕES}

A aposentadoria vivenciada como exclusão social é, portanto, um evento que não se coaduna com as estatísticas atuais, considerando-se o crescimento vertiginoso da expectativa de vida das populações de todo o mundo, nas últimas décadas. Os avanços da medicina, associados a significativas quedas nas taxas de mortalidade, e à expressiva melhoria na qualidade de vida das pessoas, têm contribuído para o aumento da população idosa no Brasil e no mundo de forma incontestável.

Em 2010, segundo dados do Instituto Brasileiro de Geografia e Estatística - IBGE, a expectativa de vida para brasileiros de ambos os sexos que nasceram a partir de 2009 subiu para 71,3 anos, tendo aumentado mais de 10 anos desde 1980. Até o final de 2050, a estimativa pode chegar aos 81,2 anos. Ainda segundo dados do Instituto, os homens continuam com uma esperança de vida menor do que a das mulheres, com uma média de 69, 4 anos contra 77 anos. 
Ratificando esse aumento da longevidade da população brasileira, Zanelli, Silva \& Soares (2010) ressaltam que, quando se institucionalizou a aposentadoria por tempo de serviço, em 1948, o brasileiro vivia apenas até por volta dos 50 anos. Ainda segundo os autores, a faixa etária de pessoas com 60 anos ou mais é a que mais cresce, correspondendo, em 2010, a 9,6\% da população brasileira. Isso tem proporcionado um aumento gradativo no tempo em que as pessoas permanecerão aposentadas, podendo chegar a viver 20 ou mais anos nessa condição.

Vale frisar, no entanto, que vivemos numa sociedade de lógica capitalista, que estigmatiza e rotula negativamente o ser velho, ao mesmo tempo em que valoriza fortemente aquele que é jovem, que produz e que procria. Ao contrário das culturas orientais, onde ser idoso é sinônimo de sabedoria e experiência, estamos inseridos num modo de produção que discrimina os mais velhos e os exclui da vida social e dos centros de poder e de decisão.

Assim, estar à margem desses modelos e perder o status de fazer parte da população economicamente ativa pode se tornar fonte de sofrimento e de inadequação social, como mostra o gráfico seguinte:

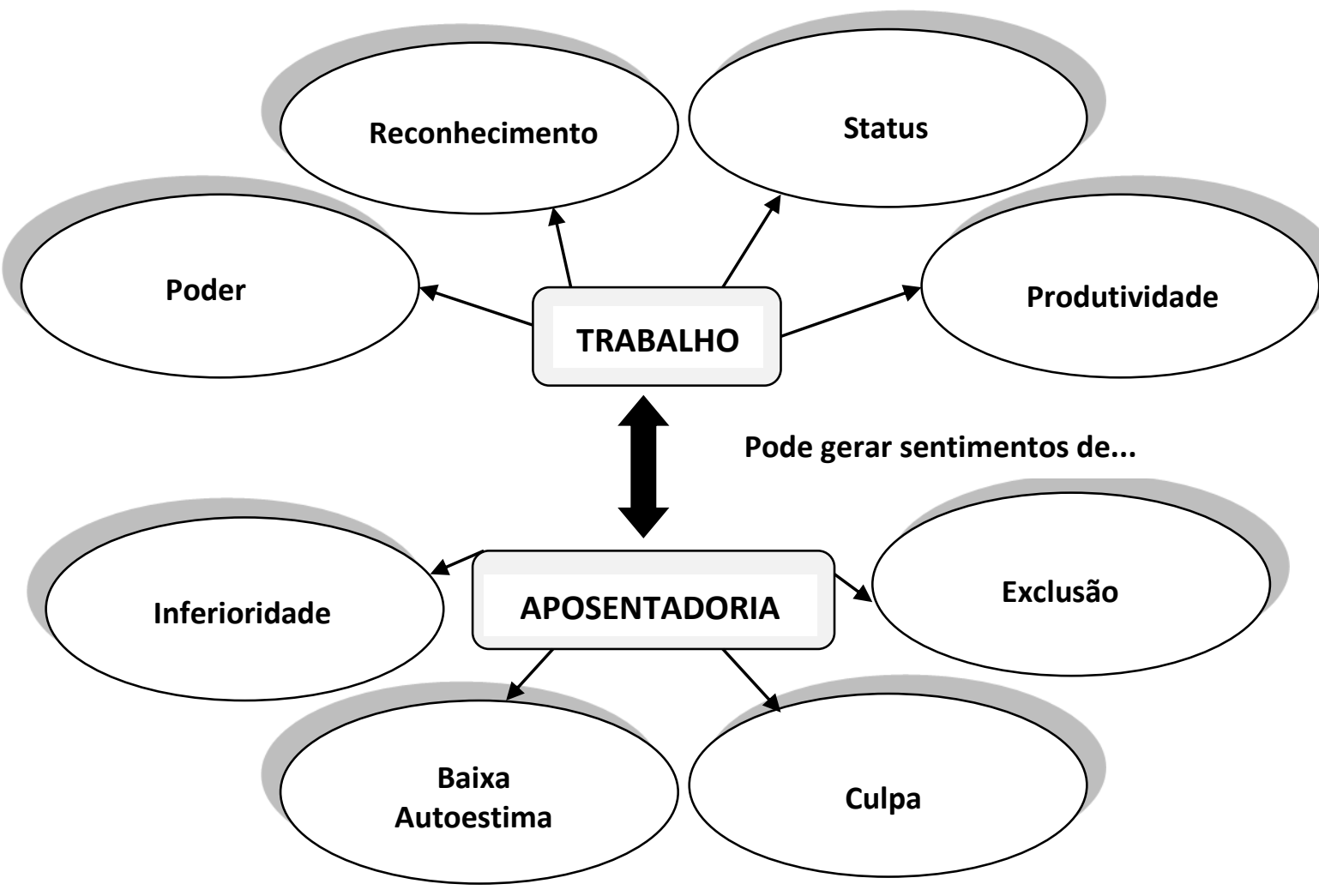

Figura 1 - Representação Trabalho X Aposentadoria. Gráfico elaborado pelas autoras.

O fato de o trabalho ser um "provedor de identidades"- pois define quem nós somos -, pode fazer com que a aposentadoria assuma, para alguns, dimensões ligadas à incapacidade, ao isolamento e à doença - verdadeiras "anti-representações" do mundo do trabalho (WHITCZAK, 2005). Como, então, aceitar sem crise o fato de estar "na contra-mão" de tudo o que foi aprendido e internalizado? 
De igual modo, a exemplo da velhice, que é compreendida como sendo uma experiência heterogênea para cada pessoa (FRANÇA, 2002; RABELO-PEREIRA, 2005), a vivência da aposentadoria também será sentida por cada um de forma diferente, em função do equilíbrio dado aos vários papéis desempenhados ao longo da vida, ao suporte emocional e familiar do sujeito, a cultura onde está inserido e, finalmente, às suas atitudes diante da vida e das oportunidades de substitutos satisfatórios para o trabalho. É uma etapa de vida extremamente importante e delicada, pois não só coincide, para muitos, com a chegada do envelhecimento, como é também um marco de mudança na dinâmica familiar - o que vai implicar em novos hábitos e papéis, não só daquele que está se aposentando. A aposentadoria, portanto, é um momento que vai requerer uma re-significação da identidade pessoal do sujeito e o estabelecimento de novos pontos de referência - e isso exige preparação (RODRIGUES et al, 2005).

Segundo Rodrigues et al (2005, p.4), haverá a necessidade de uma redefinição e mudança nos papéis desempenhados pelo sujeito, para que essa travessia seja exitosa. Será preciso o aposentado re-significar a si mesmo, uma vez que a perda do papel profissional e do vínculo com tudo o que representa o trabalho pode gerar conflitos e crises identitárias: "o aposentado deverá reconstruir sua identidade pessoal através da interiorização de novos papéis e da busca de novos objetivos de vida, num processo de redefinição de sua vida."

O impacto dessas mudanças na identidade do sujeito vai depender, fundamentalmente, de alguns fatores: da importância atribuída ao papel profissional; da qualidade do vínculo com o trabalho e da disponibilidade de substitutos satisfatórios para o mesmo. Segundo Shibata (2006), o fato de a aposentadoria ter sido desejada ou imposta, também fará muita diferença nos ajustamentos pós-carreira.

Contudo, segundo Magalhães et al (2004), haverá, com a chegada da aposentadoria, um momento de luto, onde o sujeito deverá utilizar seus mecanismos adaptativos e enfrentar as mudanças que podem se produzir em outros domínios da vida como consequência dessa perda. Este autor também cita os clássicos estudos de Atchley (1999), Hornstein \& Wapner (1985) sobre os padrões de ajustamento na aposentadoria, conforme mostra o quadro abaixo:

Tabela 1 - Padrões de ajustamento à aposentadoria (Atchley, 1999; Hornstein \& Wapner, 1985). Tabela adaptada pelas autoras.

DIFICULDADES NO AJUSTAMENTO À APOSENTADORIA

\section{FACILIDADES NO AJUSTAMENTO À APOSENTADORIA}

*Pessoas que investiam e viam sentido em outros aspectos da vida, além do trabalho, antes de se aposentarem.

*Aqueles para quem o trabalho ocupava um lugar superior na hierarquia pessoal, mas cujas metas profissionais haviam sido alcançadas (realizados profissionalmente).
*Aposentadoria forçada ou compulsória (são as mais insatisfeitas e que também apresentam saúde mais vulnerável).

\footnotetext{
*Pessoas que não atingiram suas metas

profissionais, ou mais inflexíveis com relação a

mudanças.
} 
Interpretando os estudos de Atchley (1999) e Hornstein \& Wapner (1985), pode-se concluir que a aposentadoria fica mais difícil para aqueles que sempre investiram unicamente em seu papel profissional, para quem o trabalho é, se não a única, pelo menos a atividade principal em sua vida. Neste caso, a aposentadoria poderá levá-los a descobrir ausência de sentido fora do trabalho, tornando o desligamento mais difícil, numa crise mais longa. Podem sentir-se impotentes, inúteis, sem objetivos de vida (depressão, alcoolismo, conflitos familiares, separações, problemas financeiros, adoecimentos e até a morte ocorrem com mais frequência).

No entanto, se o sujeito tem outros meios de realização além do trabalho, ele terá outras atividades de investimento sobre as quais se apoiar para redefinir sua identidade social. Assim, sua aposentadoria será vivida com mais tranquilidade e de forma menos traumática.

França (2008), ao investigar preditores positivos nas atitudes de executivos brasileiros e neozelandeses de grandes organizações frente à aposentadoria, concluiu que as maiores influências vinham de dois preditores: a influência da família e dos amigos na decisão de aposentar-se e a diversidade das atividades e relacionamentos no uso do tempo livre. Ou seja, quanto maior a variedade de atividades e ocupações no uso do tempo por parte do sujeito e quanto mais positiva for a participação da família e dos amigos na decisão de aposentar-se, mas tranquila e bem-sucedida será esta decisão.

Para Zanelli, Silva \& Soares (2010), a transição para a aposentadoria será facilitada, no entanto, se a pessoa puder vivenciar essa preparação ainda quando estiver em atividade. 0 rompimento brusco e repentino de uma rotina de trabalho estruturada há anos parece potencializar o início dos conflitos nas várias esferas da vida do sujeito. Para estes autores (p.23), "Toda a nossa vida é baseada no trabalho. Os processos de socialização primária e secundária nos preparam para isto, mesmo quando ainda não entendemos de modo mais preciso tais significados."

Esta ideia é corroborada por GUILLEMARD (1981) apud SANTOS (1990), ao afirmar que a passagem de um tempo contratado e organizado em torno do trabalho para um tempo livre de horários pode resultar em certa desorientação temporal por parte do sujeito. Se assim não fosse, o que justificaria as dificuldades, adiamentos, adoecimentos e conflitos de tantas pessoas diante da possibilidade de afastamento de uma ocupação que elas, por direito adquirido, já poderiam ter solicitado? (CRUZ, 2011). Isto pode ser observado em parte expressiva da produção científica brasileira sobre aposentadoria e pós-carreira (Santos, 1990; França, 2002, Fraiman, 2006; 2008; Stucchi, 2003; Witczak, 2005; França \& Soares, 2009; Zanelli, Silva \& Soares, 2010) que destaca, com frequência, situações de adoecimento, conflitos familiares, separações, alcoolismo, distúrbios alimentares e transtornos afetivos diversos - sendo o mais comum deles a depressão (TAVARES, NERI \& CUPERTINO, 2004; SHIBATA, 2006; RAFFA, 2006; CANIZARES, 2009), nos momentos que antecedem o evento da aposentadoria.

Assim, em decorrência destas estatísticas pouco alentadoras sobre a precária situação socioeconômica dos idosos no Brasil, em 1994 o governo aprovou a Política Nacional do Idoso (Lei no 8.842), que, entre outros avanços, propôs a criação e manutenção de programas de preparação para a aposentadoria nos setores público e privado, com antecedência mínima de dois anos antes do afastamento do trabalho, conforme veremos a seguir. 


\section{O SURGIMENTO DOS PROGRAMAS DE PREPARAÇÃO PARA O PÓS-CARREIRA}

Na esteira da Política Nacional do idoso (Lei no 8.842) foi criado, em 2003, o Estatuto do Idoso (Lei no 10.741) que, além de esclarecer os direitos sociais dos aposentados, estimula que as organizações ofereçam programas de preparação para a aposentadoria aos servidores com uma antecedência mínima de um ano antes do desligamento. São políticas públicas formuladas pelas autoridades governamentais que - embora ainda insuficientes - objetivam esclarecer e garantir os direitos da pessoa idosa, e que refletem, em seu escopo, a necessidade de preparar as pessoas para as mudanças que virão com a chegada da aposentadoria.

Os programas de preparação para o pós-carreira tiveram origem nos Estados Unidos, a partir da década de 1950, ocasião em que se limitavam a prestar informações sobre o sistema de aposentadoria e pensões. No Brasil, esses programas tiveram início no SESC de São Paulo, no final da década de 1980. À época, eram discutidos temas relativos ao envelhecimento, recursos sócio-culturais e possibilidades de serviços à comunidade, quando da entrada na aposentadoria (MUNIZ, 1996). Atualmente, algumas das principais premissas dos Programas de Preparação para o Pós-Carreira são: apresentar a aposentadoria como um momento propício ao aprendizado de coisas novas, com destaque para a prática de atividades que tragam satisfação e realização pessoal; e ênfase no planejamento, através da elaboração de um projeto de vida para os anos seguintes. Também existe compromisso ético da Instituição de não pressionar o servidor em direção à aposentadoria - esta deve ser uma decisão individual (Soares et al, 2007; França \& Soares, 2009; Zanelli, Silva \& Soares, 2010).

O termo "pós-carreira" é uma expressão criada por Bernhoeft no início da década de 1980, para designar o primeiro programa brasileiro, estruturado, de preparação de executivos para a aposentadoria. Era uma fase em que as pessoas enfatizavam prioritariamente a preparação financeira. Questões como perda da identidade organizacional ou perda da autoestima em função da ruptura com o vínculo empregatício não faziam parte do repertório de preocupações dos executivos daquela época - resume o autor (BERNHOEFT, 2009).

Para França \& Soares (2009), os PPP's têm contribuído notadamente para o bem-estar dos futuros aposentados, ao oportunizar a reflexão sobre os aspectos positivos e negativos da transição, ao mesmo tempo em que propõem a adoção de práticas e estilos de vida que promovem a saúde física e emocional dos participantes. As vantagens e reflexos para a instituição que implanta um Programa de Preparação para o Pós-Carreira também são muitos: permite que ela execute sua função de responsabilidade social; conduz os processos de aposentadoria de forma mais ética e humanizada; fortalece sua imagem externa e internamente, além de manter em equilíbrio o clima organizacional, contribuindo para a instalação de sentimentos de segurança, respeito e transparência entre a equipe dirigente e os servidores. Segundo Zanelli, Silva \& Soares (2010), manter os PPP's em funcionamento provoca transformação de valores em nível gerencial e sentimentos de bem-estar naqueles que enfrentam a transição para a aposentadoria.

\section{A EXPERIÊNCIA DE IMPLANTAÇÃO DO PROGRAMA NOVO TEMPO NO IFRN}


Considerando o objetivo deste artigo, passaremos a transcrever todo o processo de implantação do Curso de Preparação para o Pós-Carreira no IFRN, desde a sua criação até os dias atuais. A estratégia metodológica adotada será descritiva, ilustrada por alguns dos depoimentos gravados e colhidos dos participantes nos momentos das avaliações finais realizadas junto a cada uma das três turmas concluintes.

A ideia de implantar o Programa Novo Tempo através de um Curso de Preparação para o Pós-Carreira surgiu da observação de relatos pessoais, quase sempre negativos e associados a situações de pós-aposentadoria, que frequentemente surgiam durante as vivências de Psicologia do Projeto Saúde e Cidadania na Melhor Idade (IFRN/Câmpus Natal-Central). A psicólogafacilitadora desse Projeto (e uma das autoras deste artigo) concluiu pela necessidade de se falar mais a respeito de um assunto para o qual as pessoas não se preparavam, tinham pouca informação e que trazia muita angústia e sofrimento: o que fazer quando a aposentadoria chega.

Diante disso, em 2008, as duas psicólogas autoras deste artigo implantaram o PPP junto ao Departamento de Recursos Humanos/Coordenação de Assistência ao Servidor da Unidade Sede do então CEFET-RN - o qual seria posteriormente transformado em Instituto Federal de Educação, Ciência e Tecnologia (IFRN), através da Lei no 11.892/2008. O recém-implantado "Novo Tempo - Programa de Preparação para o Pós-Carreira" tinha como principais objetivos:

a) Compreender os medos e as inseguranças que podem decorrer das perdas do papel profissional, dos colegas e do ambiente de trabalho;

b) Administrar com competência e prazer uma rotina que incluirá mais tempo livre, desenvolvendo novos interesses no tocante a: cuidados com a saúde, lazer, participação política, estudos, novas ocupações e qualidade de vida;

c) Desenvolver as relações afetivas e pessoais necessárias ao fortalecimento das redes familiares e sociais;

d) Aprender a planejar-se financeiramente, gerenciando melhor seu orçamento e patrimônio, gerando assim sentimentos de segurança e estabilidade em relação ao futuro;

e) Descobrir novas (ou velhas) capacidades e talentos, que possam ser utilizados na realização de sonhos e projetos nunca tentados (ou sempre adiados).

f) Elaborar um Projeto de Vida que leve o participante a refletir, de acordo com os seus interesses, como ocupará seu tempo nos próximos anos a partir da decisão de se aposentar de uma atividade específica.

Inicialmente, a ideia era oferecer o Curso apenas aos servidores do IFRN; porém, devido à crescente demanda de pessoas da comunidade, em 2011 o Curso foi transformado em Programa de Extensão, consolidando-se como atividade permanente do Instituto. Gratuito e de caráter voluntário, o Programa Novo Tempo - que inclui o Curso de Preparação para o Pós-Carreira possibilitou, até o primeiro semestre de 2011, o planejamento estratégico pessoal e profissional de 38 pessoas, sendo 28 servidores do IFRN e 10 servidores de outras instituições, que estão há três anos ou menos da aposentadoria. As edições de 2008, 2009 e 2011 contaram, respectivamente, com 14, 11 e 13 participantes. O número reduzido de alunos por turma é opcional e constitui-se em estratégia que proporciona uma participação e aprofundamento maiores nas discussões e vivências. 
A fase que antecedeu o início do Programa, em 2008, foi destinada às etapas da divulgação, junto à comunidade do então CEFET-RN. Considerando as particularidades e sutilezas que acompanham a situação de aposentar-se, uma das principais decisões das coordenadoras foi a de não divulgar o Programa de forma restrita apenas ao público "elegível" - pessoas que se encontravam há três anos ou menos da aposentadoria. Esta informação foi dada, porém de maneira generalizada e sob a forma de notícia, a toda a comunidade. Acredita-se que, ao evitar a formação de "guetos", previne-se a segregação e a discriminação, o que dificulta o aparecimento de resistências e preconceitos ou, ainda, o surgimento de possíveis sentimentos de rejeição ou de abandono por parte daqueles servidores em vias da aposentadoria. Esta opinião é corroborada por Soares et al (2007), quando ressalta que o impulso de procurar ajuda e conhecimento e o interesse em preparar-se para a aposentadoria deve ser iniciativa do próprio sujeito.

A divulgação foi feita através dos vários meios de comunicação institucionais, a saber: internet (site do CEFET-RN), jornal mural, banner e cartazes. Também foram concedidas entrevistas para o programa "CEFET em Pauta", e as coordenadoras compareceram a reuniões pedagógicas para divulgar o evento. Paralela à divulgação, foram abertas as inscrições no Departamento de Recursos Humanos da Unidade Sede do então CEFET-RN.

O passo seguinte foi montar o perfil das necessidades do grupo de inscritos. Em relação às turmas de 2008 e 2009, foi elaborado e aplicado, no primeiro encontro, um Diagnóstico Situacional contendo dados pessoais e acadêmicos, trajetória profissional e sugestões de temas de interesse dos participantes. Havia também um espaço onde os participantes deveriam responder como se sentiam em relação à ocupação atual e à preparação para a aposentadoria.

Acreditamos ser importante não subestimar a fase diagnóstica de montagem dos perfis das turmas, elaborando programas prontos para todos os grupos. É preciso lembrar, conforme pondera Soares et al (2007), que "é preciso trabalhar com as diversidades, pois cada sujeito traz consigo sua história de vida, suas percepções e seus interesses." (p.151)

Durante a formação da terceira turma (2011), sentiu-se a necessidade de aprofundar os momentos iniciais de formação do grupo, antes do início do Curso. Houve então uma reunião informativa preliminar com os inscritos, ocasião em que foi realizada uma entrevista inicial com cada participante, sob a forma de um breve questionário. Essas informações colhidas inicialmente seriam aprofundadas com a aplicação do Diagnóstico Situacional, no primeiro encontro do Curso. No intuito de aprimorar cada vez mais o Programa, ao final do Curso os participantes da última turma preenchem um Formulário de Avaliação do Curso de Preparação para o Pós-Carreira.

\section{PREMISSAS EPISTEMOLÓGICAS E METODOLOGIA DO CURSO}

Fundamentado nas premissas de França (2002), Fraiman (2006) e Zanelli, Silva \& Soares (2010), o Programa Novo Tempo tem caráter socializador, e parte do princípio de que o planejamento é um importante redutor das angústias e inseguranças que costumam acompanhar situações de mudança ou rompimentos bruscos de rotinas de trabalho. Corrobora também com França \& Soares (2009), no sentido de que "a preparação para a aposentadoria é um recurso a 
ser disponibilizado pelas organizações, desde que garantida a oportunidade da livre escolha." (p.749). Diante disso, o Curso não tem nenhuma preocupação em levar os participantes a decidirem ou não pela aposentadoria. O objetivo maior é despertá-los para uma reflexão sobre seu momento de vida e carreira e, por conta disto, respeita-se o ritmo e as decisões (e indecisões) de cada pessoa. Conforme atesta o depoimento de uma participante:

Eu gostei muito do curso, pra mim surpreendeu todas as minhas expectativas, porque ele não só orienta a pessoa que quer se aposentar e começar uma nova vida após a aposentadoria, mas também orienta aqueles que querem continuar trabalhando.

(T., servidora técnica-administrativa do IFRN - Turma 2009)

Todas as ações do Programa enfatizam que o pós-carreira deve ser vivido como uma fase propícia a novos aprendizados e descobertas, à manutenção de atividades que sejam significativas para o indivíduo e à realização de práticas que tragam satisfação e realização pessoal. A percepção de características e sentimentos comuns entre os participantes predispõe

à formação de uma identidade grupal que promove a união, a formação de vínculos e as trocas afetivas. Esta impressão é compartilhada por Soares (2002 apud Soares et al, 2007), ao assinalar que "o trabalho de orientação em grupos possibilita identificações recíprocas, enriquecimento pessoal a partir da troca de ideias, compartilhamento de experiências, possibilidade de feedback entre os próprios membros do grupo." (p.148). É o que atesta o seguinte depoimento:

Vi que essa ansiedade não era só minha, era compartilhada por todos os amigos do curso. Eu via a aposentadoria como uma morte, como uma falta de perspectiva. Hoje não, eu já vejo como um prêmio. E isso me ajudou a decidir que agora eu vou me aposentar. Eu mereço isso, não vou ter medo. Tenho umas inseguranças, mas medo, como eu tinha antes, não tenho mais.

(R., servidora do Ministério da Fazenda - Turma 2011)

Utilizando uma metodologia predominantemente vivencial, em que prevalecem dinâmicas de grupo, jogos lúdicos, leitura de textos, exposições interativas, trabalhos em equipe, palestras e projeção de filmes - o Curso valoriza a expressão dos sentimentos, a troca de experiências e de conhecimentos entre os participantes, e a integração destes com servidores já aposentados.

O Curso de Preparação para o Pós-Carreira do IFRN/Câmpus Natal-Central possui carga horária total de 45 horas, estruturada em quatro módulos (Autoconhecimento, Relacional, Gestão Financeira e Projeto de Vida), cada um com duração de quatro semanas - à exceção do Módulo de Gestão Financeira, que foi reajustado para duas semanas, observando-se a necessidade de dar mais agilidade ao Programa. Os encontros acontecem numa frequência semanal e com duração de três horas, e a aceitabilidade desta metodologia é descrita nos seguinte relato:

O curso é de uma organização didática muito interessante; é dividido em quatro módulos, e eu acho que funcionaram muito bem esses módulos. Tivemos a oportunidade de trabalhar com material didático de alto nível de conteúdo 
teórico e científico, muito interessante. Eu acredito que vai me trazer grandes benefícios com relação a condutas que deverei adotar quando me aposentar.

(E., professor do Campus Natal-Central do IFRN - Turma 2011)

Os três primeiros encontros de cada módulo são destinados à exploração, pelas duas psicólogas, dos conteúdos propostos pelo Programa. O quarto encontro, entretanto, é destinado à realização de palestras com servidores já aposentados, que vêm contar, de maneira informal, como tem sido sua vivência no pós-carreira. A coordenação do Programa tem procurado trazer convidados com histórias de vida bem diferenciadas, não só por considerar importante conhecer tanto experiências positivas quanto as de fracasso ou insucesso, mas, principalmente, em atendimento às solicitações dos próprios participantes:

Só fiquei questionando um pouco se na escolha das pessoas deveria ter sido convidado mais alguém que estivesse sem exercer alguma atividade, para sabermos como esta pessoa se sentia com a aposentadoria.

(F., servidora técnica-administrativa do Campus Natal-Central - Turma 2008)

Os palestrantes foram muito bons, porém faltou mostrar alguém que se aposentou e está sem fazer nada. Os que vieram não vivenciaram ainda o ócio, e, com isso, ficamos sem conhecer a experiência da ociosidade.

(A., servidora técnica-administrativa do Campus Natal-Central-Turma 2008)

As palestras têm oportunizado o resgate de muitos colegas aposentados que estavam afastados há algum tempo da instituição. São eventos abertos à comunidade, e é um momento que reúne servidores aposentados, pré-aposentados e familiares. Até o final da última turma, no primeiro semestre de 2011, um total de 22 palestrantes - entre servidores aposentados e especialistas do Instituto - havia participado do Programa.

O encerramento de cada módulo tem também caráter de congraçamento: é o momento em que servidores aposentados e pré-aposentados da instituição se reencontram, compartilham abraços e experiências vividas. Na ocasião, são distribuídos brindes aos alunos-participantes, alusivos ao tema central do módulo que está se encerrando.

A atividade-fim do Programa consta da elaboração, por parte de cada participante, de um Projeto de Vida, apresentado ao final do Curso. Considerando que a aposentadoria deve ser vista como uma transição que envolve uma reorganização, redefinição e mudança nos papéis sociais exercidos pelo indivíduo (ATAÍDE, 2010), torna-se importante para o sujeito concluir o Curso refletindo, de acordo com seus interesses pessoais, como ocupará o tempo livre a partir da decisão de se aposentar de uma atividade específica.

Algumas experiências acontecidas durante esses três anos de curso merecem registro. A primeira foi a inclusão, na segunda turma (2009), de três servidores aposentados, os quais participaram ativamente das atividades, sem nenhum registro de desistência ao longo do curso. A adoção dessa metodologia, em caráter experimental, permitiu constatar, no entanto, a conveniência de se realizar Programas em separado para servidores pré-aposentados e aposentados, considerando as necessidades, expectativas e momentos de vida diferentes das duas categorias. Porém, esta constatação baseia-se unicamente em observações empíricas, 
sendo necessária a aplicação de algum instrumento de pesquisa que possa validar ou não esta impressão. Mesmo assim, os participantes relatam as experiências compartilhadas como bastante enriquecedoras, deixando evidente a importância dada ao retorno à instituição e ao reencontro com antigos colegas:

Foi um prazer estar participando deste curso, já como aposentado, o que teve grande proveito para mim. O conhecimento que eu adquiri, o fato de voltar a ficar junto com os meus colegas durante esse tempo... Fazia um tempo que eu estava afastado, mas estou muito feliz de estar participando, se Deus quiser vou concluir e vou levar muita saudade da turma, das professoras, que me deram muita alegria de estar participando, nas tardes das quartas-feiras.

(M., servidor técnico-administrativo aposentado - Turma 2009)

Outra experiência relevante e que merece estudos futuros aconteceu com a última turma, em 2011. Em decorrência de o curso ter se transformado em Programa de Extensão, passou-se a formar turmas mistas com servidores do IFRN e com servidores de outros órgãos da capital. Segundo observações das coordenadoras, a integração e os vínculos afetivos estabelecidos mostraram-se extremamente positivos. No entanto, é interessante pesquisar de que forma esta variável interfere no nível de satisfação dos participantes que são servidores do Instituto, e em que grau ela afeta a motivação e o envolvimento dos participantes.

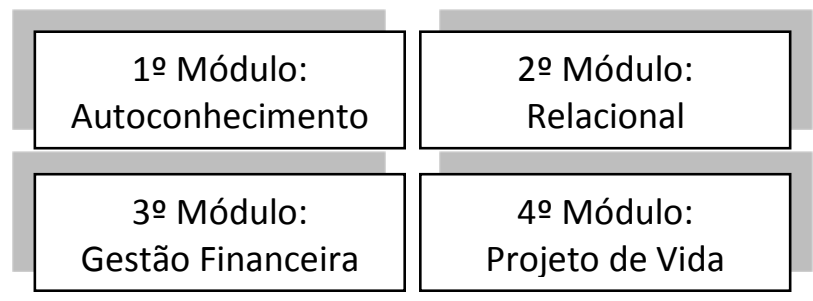

Figura 2 - Estrutura do Programa Novo Tempo.

\section{DESCRIÇÃO DOS MÓDULOS TEMÁTICOS}

\section{Módulo: Autoconhecimento. "Espelho, espelho meu... quem sou mesmo Eu?"}

O primeiro módulo tem como eixo temático reflexões sobre a pergunta: "Espelho, espelho meu... quem sou mesmo eu?". É o momento em que todos ainda estão se (re)conhecendo e delimitando espaços de poder e fala. Os participantes chegam com algum receio e desconfiança quanto a se exporem perante o grupo, numa reação natural e já esperada pelas psicólogasfacilitadoras. Porém, sem pressa e respeitando-se os ritmos de cada um, eles vão sendo levados a explorar as expectativas, medos e inseguranças que os trouxeram até ali: "Estou pronto para me aposentar?", "Está na hora de sair?", "O que eu ganho e o que eu perco ao me aposentar agora?", "O que eu tenho medo de perder?"

É um módulo em que predominam fortemente as práticas vivenciais, as quais permitem aos participantes lançar um olhar sobre si mesmos, levando-os a auto-reflexões sobre sua trajetória profissional e de vida, o vínculo e a qualidade da relação com o trabalho. Também são trabalhadas as representações sociais sobre envelhecimento e aposentadoria e seu impacto sobre a autoestima e o autoconceito dos pré-aposentados. Finaliza explorando necessidades e 
desejos não realizados, com ênfase para as competências, talentos e projetos muitas vezes adiados. Por trabalhar exaustivamente o autoconhecimento, trata-se de um módulo fundamental no processo de preparação para a aposentadoria, conforme relato desta participante:

Eu percebi que eu não me conhecia muito, a gente não tem muito tempo de olhar para si, parece-me que a gente olha mais para o outro, não é, e algumas perguntinhas ali a gente tinha que parar para pensar como é que é... como é que é você... eu achei muito interessante."

(R., professora aposentada do IFRN/Campus Natal-Central - Turma 2009)

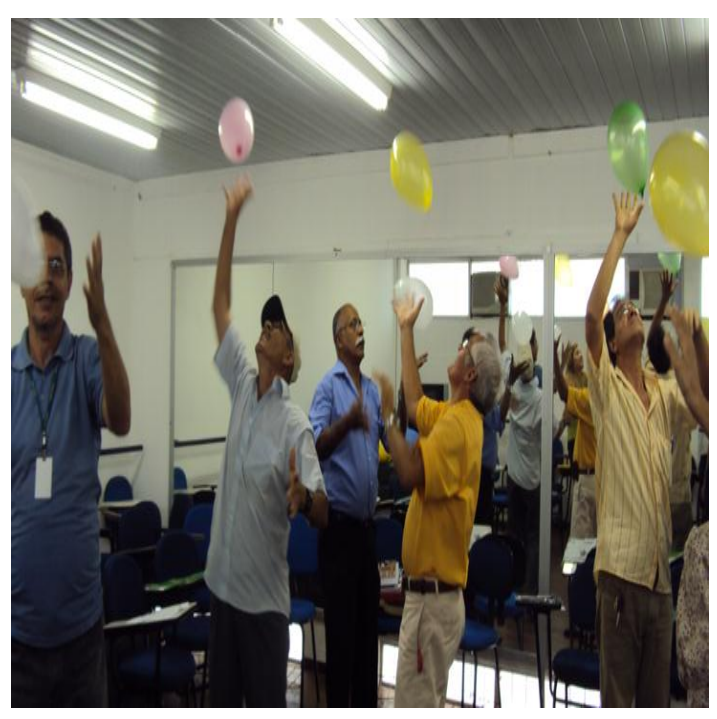

Figura 3 - Dinâmica de Grupo do Módulo de Autoconhecimento Turma 2009.

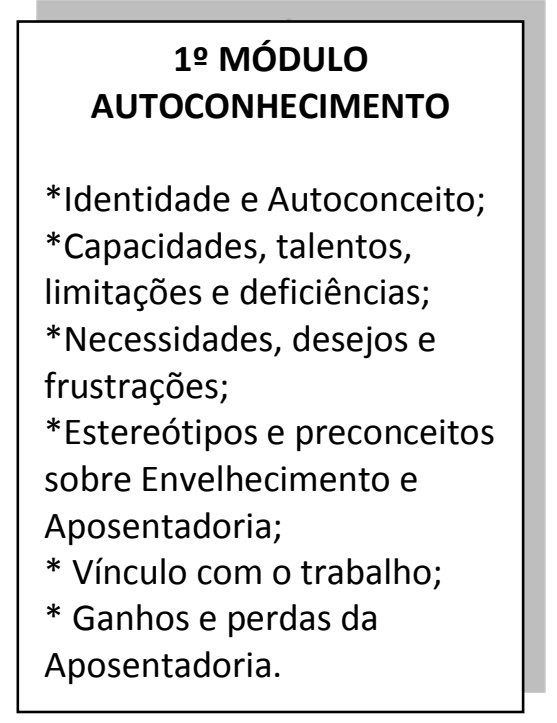

Figura 4 - Eixos temáticos do Módulo Autoconhecimento.

\section{Módulo: Relacional. "Eu e o Outro."}

A partir deste módulo, os participantes começam a se dar conta de que a aposentadoria não é um fenômeno apenas individual, mas que envolve toda a família. Percebem que haverá alterações na rotina de vida, na estruturação do tempo livre e na distribuição do poder no espaço doméstico entre os cônjuges, com a chegada da aposentadoria. Mudanças e ajustes nos papéis sociais precisarão ser feitas, e a qualidade dos relacionamentos familiares e do suporte afetivo assumem vital importância para uma aposentadoria bem-sucedida. "Quem deve parar primeiro, o homem ou a mulher? Isso faz diferença?"; "O que muda nas relações familiares com o retorno ao lar?" e "Homens e mulheres vivenciam a aposentadoria de maneira igual?" são indagações que rendem animados debates. As atividades vivenciadas promovem a afetividade intragrupo e a aproximação e os laços de amizade entre os participantes seguem de forma crescente.

Conforme é indicado por França \& Soares (2009), durante o Módulo Relacional é sugerida aos participantes a presença, em determinadas vivências ou palestras, de um familiar ou amigo convidado (cônjuge, filho, pais) - ou seja, alguém que seja significativo, e que, provavelmente, irá desfrutar com ele os anos do pós-carreira. 


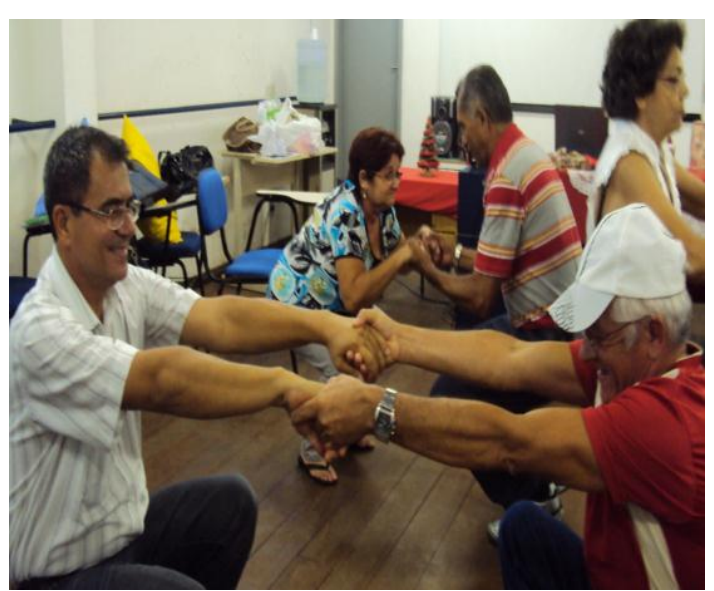

Figura 5 - Vivência do Módulo Relacional - Turma 2009.

\section{MÓDULO \\ RELACIONAL}

* Relacionamento familiar e conjugal;

* Distribuição do poder no espaço doméstico;

*Fortalecimento das redes

familiares e sociais;

*Saúde e qualidade de vida;

* Novas ocupações e novos papéis sociais;

\section{Figura 6 - Eixos temáticos} do Módulo Relacional.

\section{Módulo: Gestão Financeira. "Pensando a curto, médio e longo prazo"}

Este terceiro módulo do PPP tem características peculiares, que lhe conferem um formato diferenciado. Tanto que um ajuste importante foi feito em sua carga horária: observou-se que o Módulo de Gestão Financeira poderia ser reduzido de quatro para dois encontros, de forma a tornar o Programa mais ágil. Assim, a primeira edição foi realizada com 51 horas e as demais com 45 horas, sem prejuízo algum de conteúdo.

Por focalizar temas mais técnicos e, muitas vezes, ligados à legislação trabalhista e previdenciária, a coordenação do Programa optou por dar um maior destaque à presença de convidados especialistas, certamente mais capacitados para esclarecerem com mais conhecimento e propriedade dúvidas como as seguintes: "Como me organizar para minimizar as perdas financeiras?"; "Como manter meu padrão de vida?"; "Como posso ganhar mais dinheiro estando aposentado?

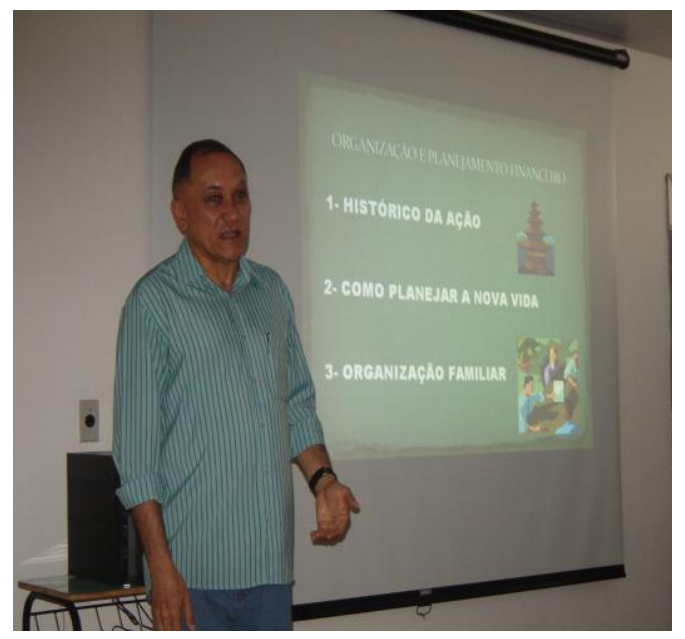

Figura 7 - Palestra no Módulo de Gestão Financeira - Turma 2008.

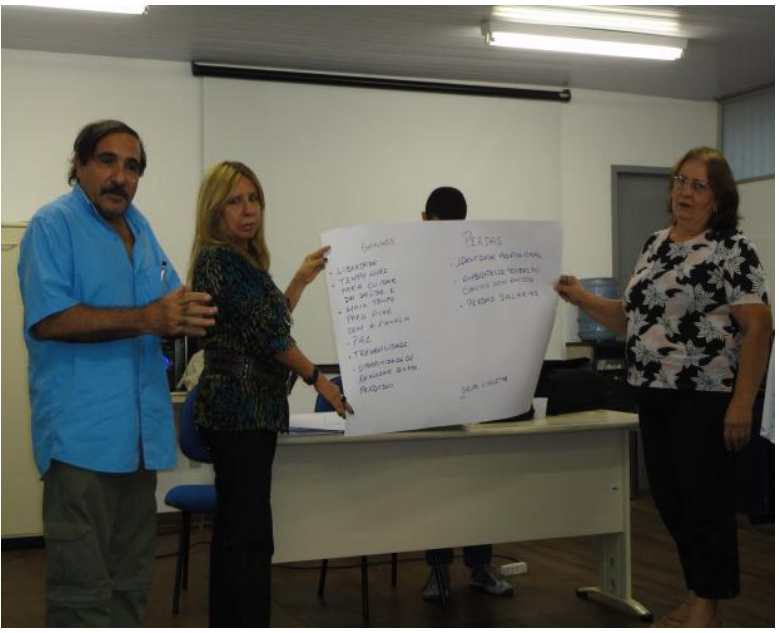

Figura 8 - Atividade do Módulo de Gestão Financeira - Turma 2011. 


\section{3o MÓDULO}

FINANCEIRO

*Orçamento

doméstico;

* Organização e

Planejamento

Financeiro;

*Aspectos legais, trabalhistas e previdenciários da Aposentadoria;

*Bens e

Patrimônios.
"Ao participar do curso percebi que as coisas não eram exatamente aquilo que a gente imagina, que a gente estava pensando, aquilo que eu imaginava. Existem certos determinados detalhes, certas determinadas coisas que foram importantes serem vistas, analisadas e refletidas, para possibilitar que nós tomássemos alguma decisão com mais segurança, com mais determinação e com menos erros".

(N., professor do Campus Natal-Central do IFRN, - Turma 2009)

Figura 9 - Eixos temáticos do Módulo Financeiro.

40 Módulo: Projeto de Vida: "O que você vai ser, agora que cresceu?..."

O 4 módulo encerra o Programa. É o momento mais importante de todo o curso, quando cada participante apresenta para a turma o seu Projeto de Vida, ou seja: Como eu me vejo daqui a cinco anos? O que eu gostaria de estar fazendo? São reflexões importantes, que requerem tempo para maturação e elaboração.

Segundo França \& Soares (2009), a importância maior do Projeto de Vida reside no fato de que a pessoa poderá experimentar novas situações, desenvolver habilidades, aptidões e ainda descobrir novos interesses, em áreas tão diversas quanto a saúde, os investimentos, as atividades intelectuais, domésticas, culturais, de lazer, dentre outras. Para Quick \& Moen (1998), o Projeto de Vida pode, inclusive, incluir o trabalho - seja formal ou informal, voluntário ou de forma remunerada.

Diante disso, um roteiro com as especificações e todas as orientações sobre como elaborar o Projeto de Vida são entregues aos participantes, ainda no módulo anterior. O Projeto de Vida é apresentado a todo o grupo no dia do encerramento do Programa - e transformou-se no que eles carinhosamente chamam de "TCC - Trabalho de Conclusão de Curso". 


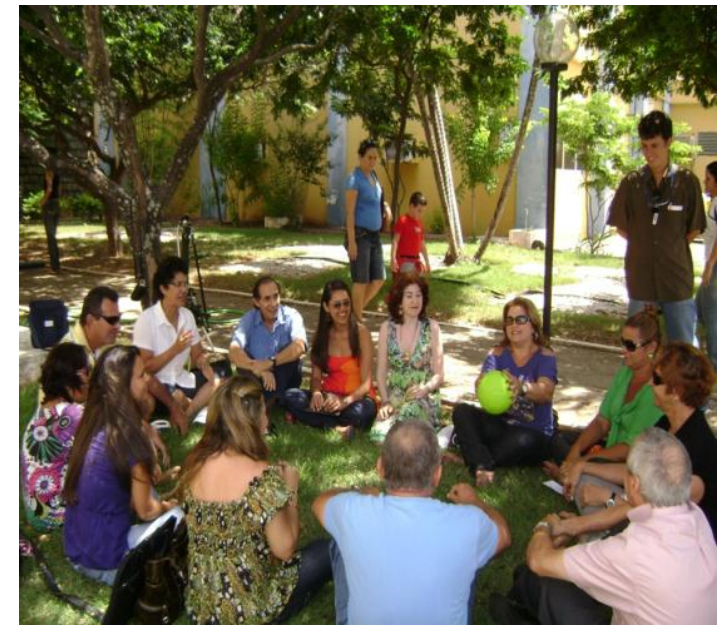

Figura 10 - Aula prática do Módulo Projeto de Vida - Turma 2008.

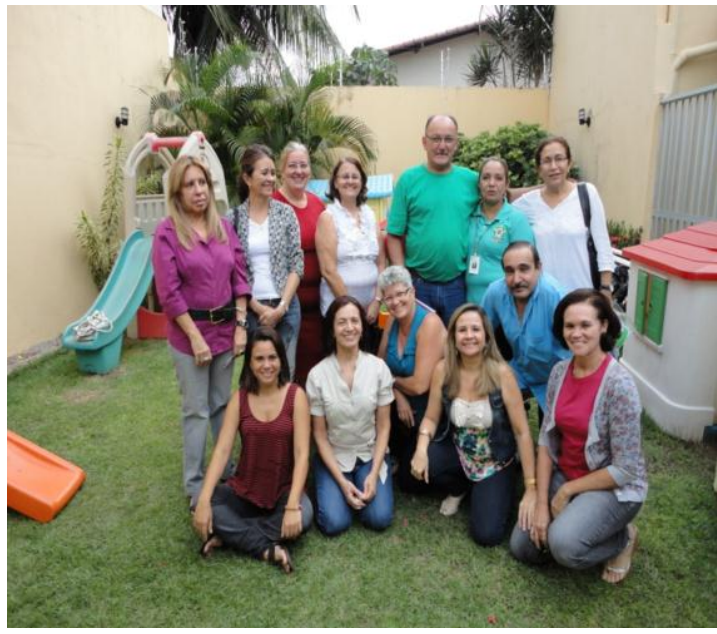

Figura 11 - Visita à Casa de Apoio à Criança com Câncer - Turma 2011.

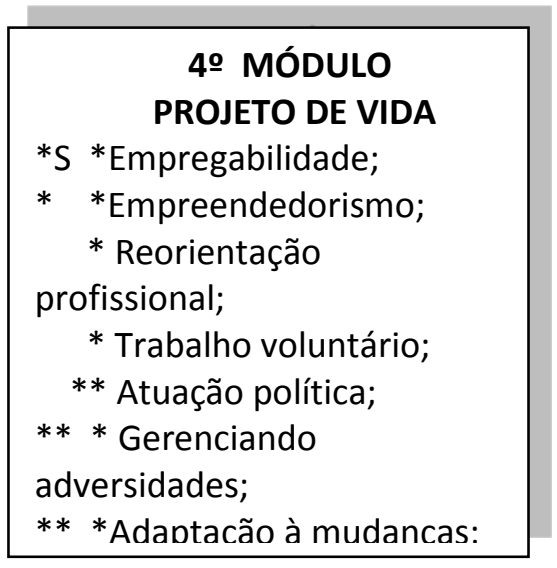

Figura 12 - Eixos temáticos do Módulo Projeto de Vida
"Tivemos momentos muito reflexivos, momentos importantíssimos, que vieram subsidiar a todos nós nas nossas escolhas. E uma das coisas mais marcantes que eu achei foi uma reflexão que falava sobre a amizade. Como é importante resgatar essas amizades. Pois a aposentadoria não é o fim, é apenas o começo de uma outra carreira."

(I., servidora do IBAMA - Turma 2011)

dia a dia a gente vai fazendo as tarefas, participando dos encontros e discutindo os problemas, tendo palestras dos colegas que já participaram do evento... Estou me sentindo muito satisfeito e graças a Deus eu consegui dar um rumo a essa minha aposentadoria com os planos que eu tracei."

(J.R., professor do Campus Natal-Central do IFRN - Turma 2011)

\section{CONSIDERAÇÕES FINAIS}

A aposentadoria é uma fase que poderá ser vivida como crise ou como oportunidade, como fim ou recomeço. Nas palavras de Caldas (2009), "somos nós que atribuímos o significado que esta fase da vida terá" - ou seja, não é possível a auto-realização sem que o sujeito atribua sentido às suas ações. Para tanto, é fundamental que os projetos de vida no pós-carreira sejam orientados, prioritariamente, para a auto-realização.

Nesse aspecto, os programas de preparação para a aposentadoria têm se revelado um espaço de reflexão por excelência para que o sujeito desenvolva o autoconhecimento e efetive a transição do trabalho para a aposentadoria com planejamento, segurança e tranquilidade. 
Segundo Zanelli, Silva \& Soares (2010), esses programas, ao estimularem a elaboração de projetos vida voltados para o desenvolvimento continuado e para uma aposentadoria ativa, convergem para o estabelecido pela Política do Envelhecimento Ativo proposta pela Organização Mundial de Saúde (WHO, 2002): garantir e estimular a mobilidade, a participação social e a independência da pessoa idosa em relação à sociedade, além da promoção de programas de preparação para a aposentadoria para aqueles que desejam ou precisam sair do mercado de trabalho.

Concordamos com França (2008), quando esclarece que a educação para a aposentadoria não precisa ser necessariamente organizada sob a forma de um programa - é essencial, no entanto, que as organizações disponibilizem a seus servidores orientações e espaços de convivência e aconselhamento, seja individualmente ou em grupo, para se falar dos aspectos dessa fase da vida.

Ao concluir a terceira turma do Curso de Preparação para o Pós-Carreira, em 2011, é importante contabilizar os erros e reforçar os acertos. Ao priorizar-se o livre-arbítrio dos participantes em relação à continuidade ou à reconstrução de suas vidas longe do trabalho institucional no pós-carreira, as avaliações dos participantes levam a crer que se está no caminho certo. O Curso Pós-Carreira contabiliza, ao final de três turmas com 38 "alunos formados", oito pedidos de aposentadoria. No entanto, levar o participante a aposentar-se ou não, não significa conforme já frisado anteriormente - a pretensão maior do Curso; não se constitui, inclusive, em nenhuma de suas metas. No entanto, sentem-se os objetivos serem plenamente alcançados quando se percebe que os participantes estão se permitindo parar e lançar um olhar para dentro de si mesmos, redescobrir-se e resgatar suas trajetórias de vida e carreira, reconhecendo suas vitórias e também seus dissabores, e projetando-se, com segurança, em direção ao futuro. Permitindo-se duvidar, questionar, rever, gostar, voltar atrás... Ou, simplesmente, sentir saudades... Conforme depoimento abaixo:

"O curso me levou à minha adolescência, quando eu tinha meus 13, 14 anos, em que o domingo à tarde era o domingo do "matiné", ou do "assustado", e eu não perdia um dia. Então, essas quartas-feiras passaram a ser para mim isso aí, né, me voltou a essa obrigação de um momento que para mim eu estou feliz, eu me divertia de estar com vocês. Eu garanto uma coisa: que o material, a convivência que vocês nos proporcionaram, é suficiente, mais que suficiente para que a gente tenha o mínimo necessário pra nós começarmos nosso projeto após essa carreira. Eu gostaria de dizer para vocês que vou sentir saudades de vocês não quando me aposentar, mas logo no momento em que se encerrar esse curso."

(D.M., professor do Campus Natal-Central do IFRN - Turma 2009)

Conclui-se, finalmente, que o desligamento do mundo do trabalho é um momento que necessita de preparação, de aceitação e, principalmente, de planejamento de um projeto de vida que possibilite que o pós-carreira seja vivido de forma ativa e participativa. Urge, portanto que as instituições assumam o compromisso social de apoio e de orientação a seus funcionários quando da chegada da aposentadoria, para que esta etapa da vida possa ser vivida, realmente, como um novo tempo. 


\section{REFERÊNCIAS BIBLIOGRÁFICAS}

1. ATAÍDE, J.F. Aposentadoria: nunca é cedo para se pensar. Disponível em http://www.dicasprofissionais.com.br. Acesso em: 21 de setembro de 2011.

2. AURÉLIO, O mini dicionário da língua portuguesa. 4ạ. edição revista e ampliada do mini dicionário Aurélio. 7ạ impressão - Rio de Janeiro, 2002.

3. BALTES, P. \& BALTES, M. Psychological perspectives on successful aging: the model of selective optimization with compensation. In: Baltes, P. \& Baltes, M. (eds.) Successful aging: the perspectives from the behavioral sciences. Cambridge: Cambridge University Press, 1990.

4. BARDIN, L. Análise de Conteúdo. Trad. Luís Antero Reto e Augusto Pinheiro. Lisboa: Edições 70, 2002.

5. BERNHOEFT, R. Origens e perspectivas do pós-carreira no Brasil. P@rtes (São Paulo). V.00 p. eletrônica, julho de 2009. Disponível em http://www.partes.com.br. Acesso em: 20 de setembro de 2011.

6. BRASIL. Estatuto do Idoso. Lei Federal no 10.741, de 01 de outubro de 2003.

7. BRASIL. Política Nacional do Idoso. Lei no 8.842, de 04 de janeiro de 1994.

8. BRASIL. Rede Federal de Educação Profissional, Científica e Tecnológica. Lei no 11.892, de 29 de dezembro de 2008.

9. CALDAS, C.P. Preparação para uma aposentadoria ativa. In J.C.B. Júnior (Org.).

Empreendedorismo, trabalho e qualidade de vida na terceira idade - 1.ed - São Paulo: Edicon, p.141-151, 2009.

10. CANIZARES, J.C.L. Fatores de risco à senilidade na transição à aposentadoria. Tese de Doutorado - Faculdade de Medicina da Universidade de São Paulo, 2009.

11. CRUZ, M.A.G. Adiando o pós-carreira: um estudo sobre os fatores que levam servidores federais a adiar a aposentadoria em uma instituição de pesquisa. Dissertação de Mestrado em Gestão e Desenvolvimento Regional - Universidade de Taubaté, 2011.

12. CARLOS, S.A., JACQUES, M.G.C., LARRATÉA, S.V., HEREDIA, O.C. Identidade, aposentadoria e terceira idade. Estudos Interdisciplinares do Envelhecimento, Porto Alegre, v.1, p.77-89, 1999.

13. FILHO, O. de A.V. Aposentadoria espontânea - uma nova leitura de seus efeitos no contrato do emprego. Revista Jus Navigandi. Disponível em http://www.jusbrasil.com.br. Acesso em: 19 de setembro de 2011.

14. FRAIMAN, A. Curso de Formação de Facilitadores em PPA - Programa de Preparação para o Pós-Carreira - Manual de Treinamento. São Paulo: ICSS/SINDAP, 2006.

15. FRANÇA, L.H. Repensando a aposentadoria com qualidade - um manual para facilitadores em programas de educação para a aposentadoria [Livro eletrônico]. Rio de Janeiro: Universidade Aberta da Terceira Idade/UNATI/UERJ, 2002.

16. . O desafio da aposentadoria: o exemplo dos executivos do Brasil e da Nova Zelândia. Rio de Janeiro: Rocco, 2008. 
17. FRANÇA, L.H. \& SOARES, D.H.P. Preparação para a aposentadoria como arte da educação ao longo da vida. Psicologia, Ciência e Profissão, 29(4), p.738-751, 2009.

18. IBGE - Instituto Brasileiro de Geografia e Estatística. Brasil. Rio de Janeiro: Fundação IBGE. Disponível em http://www.ibge.gov.br. Acesso em: 20 de setembro de 2011.

19. MAGALHÃES, M. de O. et al. Padrões de ajustamento na aposentadoria. Aletheia, n.19, Canoas, jun. 2004.

20. MUNIZ, J.A. PPA: Programa de preparação para o amanhã. Estudos de Psicologia, v.2, n.1, p.198-204, 1996.

21. QUICK, H.E. \& MOEN, P. Gender, employment, and retirement quality: A life course approach to the differential experiences of men and women. Journal of Occupational Health Psychology, 3(1), 44-64, 1998.

22. RABELO-PEREIRA, T. Histórias de vida de mulheres idosas - um estudo sobre o bem-estar subjetivo na velhice. Natal, 2005. Dissertação de Mestrado em Psicologia - Universidade Federal do Rio Grande do Norte, 2005.

23. RAFFA, L.O. Síndromes depressivas e aposentadoria: a conseqüência da tomada do sujeito como representação mercadológica no limite da educação. Tese de Doutorado Universidade Estadual de Campinas, 2006.

24. RODRIGUES, M. et al. A preparação para a aposentadoria: o papel do psicólogo frente a essa questão. Rev. Bras. Orientação Profissional, v.6, n.1, p.53-62, jun. 2005.

25. SANTOS, M. de F. de S. Identidade e Aposentadoria. São Paulo: EPU, 1990.

26. SOARES, D.H.P. et al. Aposenta-ação: programa de preparação para aposentadoria. Estudos interdisciplinares sobre o envelhecimento, v.13, p.123-134, 2007.

27. SHIBATA, L.H. Em busca de um novo caminho. O pós-carreira como oportunidades de realizações de potencialidades. São Paulo, 2006. Dissertação de Mestrado em Psicologia Clínica - Pontifícia Universidade Católica de São Paulo, 2006.

28. STUCCHI, D. O curso da vida no contexto da lógica empresarial: juventude, maturidade e produtividade na definição da pré-aposentadoria. In M.M. Lins de Barros (Org.) - Velhice ou Terceira Idade? Estudos antropológicos sobre identidade, memória e política. 3.ed. - Rio de Janeiro: Editora FGV, 2003.

29. TAVARES, S.S., NERI, A.L. \& CUPERTINO, A.P. Saúde emocional após a aposentadoria. In A.L. Neri e M.S. Yassuda (Orgs.) - Velhice bem-sucedida, aspectos afetivos e cognitivos, p.91-110, Campinas: Papirus, 2004.

30. WITCZAK, M.V.C. Envelhecer ao aposentar-se? Discutindo a aposentadoria masculina, o envelhecer e o subjetivar. Santa Cruz do Sul: EDUNISC, 2005.

31. WHO. Envelhecimento ativo: uma política de saúde. Brasília: Organização Pan-americana da Saúde, 2005. Disponível em: http://bvsms.saude.gov.br. Acesso em: 02/09/2011.

32. ZANELLI, SILVA \& SOARES. Orientação para aposentadoria nas organizações de trabalho: construção de projetos para o pós-carreira. Porto Alegre: Artmed, 2010. 